\title{
Time trends in diagnostic testing for primary ciliary dyskinesia in Europe
}

To the Editor:

Despite recent advances in diagnostic methods, diagnosis of primary ciliary dyskinesia (PCD) remains complex. We need a combination of different diagnostic tests, and all have their limitations [1]. In 2009, the first European Respiratory Society (ERS) Task Force on PCD in children published recommendations [2], suggesting that: 1) nasal nitric oxide (nNO) should be measured to screen for PCD in patients aged $\geqslant 5$ years [3]; and 2) video microscopy (VM) analysis of ciliary beat pattern and frequency [4] plus electron microscopy (EM) [5] should be the key confirmatory diagnostic tests. Genetic testing was not recommended as part of the initial diagnostic testing, but as an additional test for inconclusive cases. The recommended test combination was $\mathrm{nNO}, \mathrm{VM}$ and $\mathrm{EM}$ for patients aged $\geqslant 5$ years and VM plus EM for younger patients.

In 2017, a second ERS Task Force on PCD diagnosis revised the accumulated literature and published evidence-based guidelines [6]. Although evidence-based guidelines have become the norm in research, their practical implementation can be challenging [7]. We wanted to assess whether the 2009 diagnostic recommendations had been implemented and how diagnosis of PCD changed in Europe over time. This knowledge will help to improve implementation of the new guidelines.

We analysed data from the international PCD cohort (iPCD) (details are published elsewhere [8]). By May 2018, the iPCD included data on 3733 patients from 26 centres in 21 countries. For this study, we included all datasets from European centres that tested patients with PCD, both before and after 2009, and had complete information on nNO, EM and VM testing. We excluded patients in whom diagnosis was based only on clinical presentation and patients with unknown dates of testing.

We included 2108 patients from 16 centres (11 European countries) (Belgium, Cyprus, Czech Republic, France, Germany, Italy, Norway, Poland, Switzerland, Turkey and the UK); 51\% were male, 818 patients (39\%) had been diagnosed before and 1290 after 2009. All three recommended tests were available in all countries, with the exception of Norway where VM testing was not available neither before nor after 2009.

Based on the 2009 recommendations, we only considered nNO measurements in patients aged 5 years or older [2]. We considered the $\mathrm{nNO}$ test as positive when $\mathrm{nNO}$ was below $77 \mathrm{~nL} \cdot \mathrm{min}^{-1}[9,10]$. VM had been performed with different techniques over time, with high-speed video analysis being the most commonly used technique in recent years. We classified VM and EM results as pathological based on information provided by the centres on the beat frequency, beat pattern and cilia ultrastructure. For each patient, we defined the calendar year of diagnosis based on the date of the earliest positive test result. We then assessed whether there was a change over time in the proportion of diagnosed patients who had received a) the recommended test combination, or b) any single test. We compared the proportion of patients with the recommended test combination (VM and EM for patients aged $<5$ years and $\mathrm{nNO}$, VM and EM for older patients) for the two time periods, before and after 2009. We used R version 3.1.2 for all analyses.

Overall, we found no significant trend over time in the use of the test combination. The three tests had been used in 54\% of patients diagnosed before 2009 and in $57 \%$ after 2009 ( $p=0.15$ ) (figure 1). In preschool children, the proportion diagnosed with the recommended combination was $72 \%$ before and $75 \%(p=0.47)$ after 2009; in older patients it increased from $46 \%$ to $52 \%(p=0.03)$. Results differed

@ERSpublications

Adherence to the 2009 ERS task force diagnostic recommendations was low. To further improve PCD diagnosis, we must be more diligent and engaging in implementing the new evidence-based guidelines published in 2017. http://bit.ly/2zvjpBh

Cite this article as: Halbeisen FS, Shoemark A, Barbato A, et al. Time trends in diagnostic testing for primary ciliary dyskinesia in Europe. Eur Respir J 2019; 54: 1900528 [https://doi.org/10.1183/ 13993003.00528-2019]. 

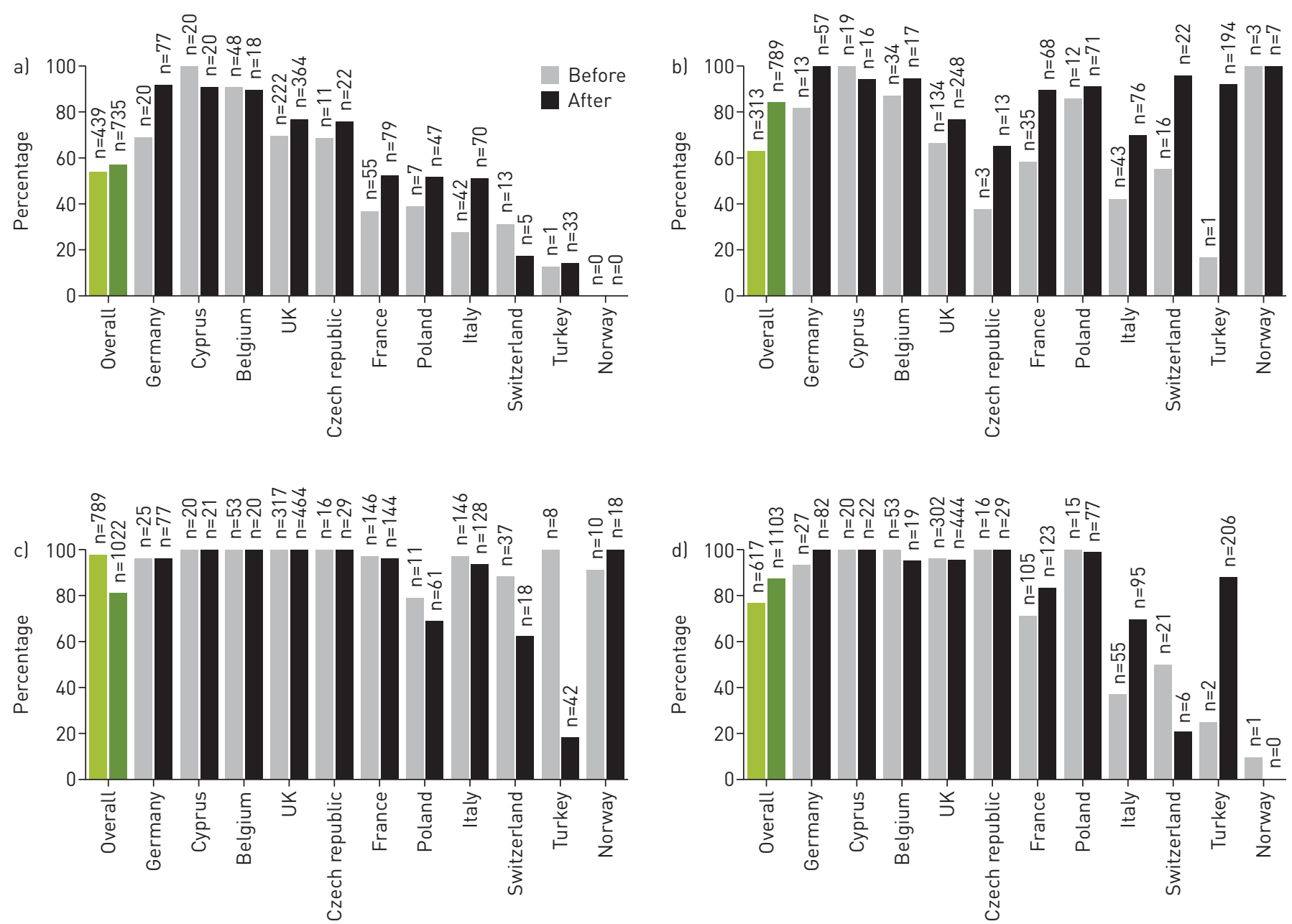

FIGURE 1 Proportion of performed diagnostic tests in European countries before and after the 2009 consensus statement on primary ciliary dyskinesia diagnostics.

between countries. Few countries (e.g. Belgium, Cyprus) combined all three tests already before 2009 for most patients and continued to do so after 2009. In Germany, the UK and the Czech Republic, the combined use of all three tests was already common before 2009 but increased even more after 2009, with almost three-quarters of the patients tested according to recommendations. The remaining countries (Turkey, Switzerland, Italy, France and Poland) showed little or no change over time. In these countries, less than half of the patients, were tested with all three approaches even in the later period.

Nasal NO testing increased overall from $63 \%$ before 2009 to $84 \%$ afterwards $(p<0.001)$. This increase was seen in most countries (figure 1). After 2009, nNO was measured in over three-quarters of patients in all countries, except in the Czech Republic (65\%), Italy (70\%) and the UK (77\%). Electron microscopy was frequently performed before $2009(97 \%)$ but decreased to $80 \%(\mathrm{p}<0.001)$ in the later period. Its use became less common in Poland (79\% to $69 \%)$, Switzerland ( $88 \%$ to $62 \%$ ) and Turkey (100\% to $18 \%$ ), in all other countries it remained stable or increased after 2009. Video microscopy analysis increased overall from $76 \%$ to $87 \%(\mathrm{p}<0.001)$. This was mainly because the use of VM for PCD diagnosis increased considerably in Italy (36\% to $69 \%)$ and Turkey (25\% to $88 \%)$. In most countries, its use remained stable, while in Switzerland (50\% to $21 \%$ ) it decreased substantially.

This is the first multi-national study that compared diagnostic testing in PCD patients between countries and over time. Although a large number of countries contribute to iPCD, some had to be excluded for this analysis as they only contributed patients diagnosed after 2009 to the iPCD cohort. Thus, our study describes how the consensus recommendations were implemented in 11 countries. They are not representative for all European countries, but only for those with established PCD diagnostic protocols. In this analysis, we included both children and adults. However, when we limited the analysis to children only, for whom the 2009 recommendations were intended, results remained similar. 
Our results suggest that the implementation of the recommended diagnostic combination of nNO, EM and VM testing after the 2009 consensus statement remained low. This reflects the complex nature of PCD diagnostics and the regional resources. Many countries continued to perform only one or two of the recommended tests. There are several explanations for this observation. First, the availability of local resources could have led to the development of alternative diagnostic pathways, which may have been most appropriate for the local situation at that time. All PCD diagnostic tests need specialised expensive equipment and personnel experienced in analysis of VM and EM results, which are not available in all settings. Limited resources or decentralised healthcare might not have allowed to set up diagnostic centres with scientists experienced in all methods. For countries with limited resources cost-effective alternatives for diagnostic testing have been suggested, which might provide an acceptable diagnostic accuracy [11]. Second, since 2009, the use of other methods including genetic testing [12,13] and immunofluorescence microscopy $[14,15]$ became more widespread. These newer methods might have been used instead of the recommended tests in some centres. Lastly, the lack of sufficient evidence supporting the use of some diagnostic tests in 2009 might have prevented some countries to implement the full set of recommended tests but let them to develop their own diagnostic algorithms. We found considerable heterogeneity between countries in the use of the three tests. Overall, countries with low prior use of nNO showed improvement and $\mathrm{nNO}$ is now used in most patients aged $\geqslant 5$ years suspected for PCD. For the proportion of patients who were still not tested after 2009, we speculate that nNO was not performed as a screening test, and the primary investigators chose to do directly one or both of the other tests. In this case, if the diagnosis was already established based on the results of the other tests, the patients might not have been invited post hoc to perform also nNO measurement. This would be in line with the recommendations. We found that use of EM analysis decreased, and VM increased, suggesting that there might be a shift from EM to VM overall. Possible reasons are the realisation that a significant proportion of patients have normal EM findings [16] and the high costs of EM analysis combined with an increased availability of $\mathrm{VM}$, so that only patients with inconclusive VM results were referred for EM testing. The overall changes in use of VM and EM analyses were strongly affected by the marked increase in VM and decrease in EM analysis in Turkish patients. This shift is explained by the development of a new PCD centre, which uses VM more and EM less frequently.

The 2009 PCD diagnostic consensus is a typical example of how difficult it is to implement guidelines in clinical practice. Even though the recommendations were widely presented in scientific conferences and meetings, improving knowledge is not sufficient to change daily practices. A synthesis of systematic reviews on clinical guideline implementation strategies showed that passive dissemination was an ineffective measure and that implementation strategies should be multifaceted, and actively engage clinicians throughout the process [7]. In the case of PCD diagnosis, implementation is further hindered by fragmentation of national diagnostic services in many centres and the cost of diagnostic equipment. In our study, countries with limited resources (e.g. Poland, Turkey) or decentralised diagnosis (e.g. France, Italy, Switzerland) performed the recommended test combination less frequently, than countries with more resources (e.g. Germany, Belgium, UK) or established centralised PCD diagnosis (e.g. Cyprus, UK). National and multi-national collaborations, such as the European Reference Network for respiratory diseases (ERN-Lung; https://ern-lung.eu/) might play an important role in the future to facilitate centralised diagnosis and standardised patient care. With the further development and improvement of diagnostic tests for PCD and with new centres emerging, which might lack the necessary expertise, there is an increased need for national and international collaboration in PCD diagnostic testing.

Overall, we found a low adherence to the 2009 consensus recommendations mainly due to the decrease in use of EM analysis in some countries. This resulted in low use of the recommended test combination. To further improve PCD diagnosis, we must be more diligent and engaging in implementing the new evidence-based guidelines published in 2017, putting more emphasis on establishing specialised diagnostic centres and close international collaboration.

Florian S. Halbeisen $\oplus^{1}$, Amelia Shoemark ${ }^{2,3}$, Angelo Barbato ${ }^{4,5}$, Mieke Boon ${ }^{6}$, Siobhan Carr $\circledast^{2}$, Suzanne Crowley ${ }^{7}$, Rob Hirst ${ }^{8}$, Bulent Karadag', Cordula Koerner-Rettberg ${ }^{10}$, Michael R. Loebinger ${ }^{11}$, Jane S. Lucas $\odot^{12}$, Bernard Maitre $\odot^{13,14}$, Henryk Mazurek ${ }^{15}$, Uğur Özçelik ${ }^{16}$, Vendula Martinů ${ }^{17}$, Nicolaus Schwerk ${ }^{18}$, Guillaume Thouvenin ${ }^{13,19,20}$, Stefan A. Tschanz $\circledast^{21,22}$, Panayiotis Yiallouros ${ }^{23}$, Myrofora Goutaki $\circledast^{1,24,25}$ and Claudia E. Kuehni $\circledast^{1,24,25}$

${ }^{1}$ Institute of Social and Preventive Medicine, University of Bern, Bern, Switzerland. ${ }^{2}$ Dept of Paediatrics, Primary Ciliary Dyskinesia Centre, Royal Brompton and Harefield Foundation Trust, London, UK. ${ }^{3}$ School of Medicine, University of Dundee, Dundee, UK. ${ }^{4}$ Italian PCD Consortium. ${ }^{5}$ Dept of Paediatrics, University of Padova, Padova, Italy. ${ }^{6}$ Dept of Paediatrics, University Hospital Gasthuisberg, Leuven, Belgium. ${ }^{7}$ Unit for Paediatric Heart, Lung, Allergic Diseases, Rikshospitalet, Oslo, Norway. ${ }^{8}$ Dept of Infection, Immunity and Inflammation, Institute for Lung Health, University of Leicester, Leicester, UK. ${ }^{9}$ Dept of Pediatric Pulmonology, Marmara University, School of Medicine, Istanbul, Turkey.

${ }^{10}$ Dept of Paediatric Pneumology, University Children's Hospital of Ruhr University Bochum, Bochum, Germany.

${ }^{11}$ Host Defence Unit, Royal Brompton and Harefield NHS Foundation Trust, London, UK. ${ }^{12}$ Primary Ciliary Dyskinesia 
Centre, NIHR Respiratory Biomedical Research Centre, University of Southampton, Southampton, UK. ${ }^{13}$ French Reference Centre for Rare Lung Diseases. ${ }^{14}$ Hopital intercommunal de Créteil, Service de Pneumologie, DHU ATVB, Université Paris Est Créteil, Paris, France. ${ }^{15}$ Dept of Pneumonology and Cystic Fibrosis, Institute of Tuberculosis and Lung Disorders, Zdrój, Poland. ${ }^{16}$ Dept of Pediatric Pulmonology, Hacettepe University Faculty of Medicine, Ankara, Turkey. ${ }^{17}$ Pediatric Dept, Charles University Prague and University Hospital Motol, Prague, Czech Republic. ${ }^{18}$ Clinic for Paediatric Pulmonology, Allergiology and Neonatology, Hannover Medical School, Hannover, Germany. ${ }^{19}$ Paediatric Pulmonary Dept, Trousseau Hospital APHP, Sorbonne Universities and Pierre et Marie Curie University, Paris, France. ${ }^{20}$ Sorbonne Université, INSERM, Centre de Recherche Saint-Antoine, CRSA, Paris, France. ${ }^{21}$ Swiss PCD registry (CH-PCD). ${ }^{22}$ Institute of Anatomy, University of Bern, Bern, Switzerland. ${ }^{23}$ Medical School, University of Cyprus, Nicosia, Cyprus. ${ }^{24}$ Paediatric Respiratory Medicine, Children's University Hospital of Bern, University of Bern, Bern, Switzerland. ${ }^{25}$ Both authors contributed equally.

Correspondence: Claudia E. Kuehni, University of Bern, Institute of Social and Preventive Medicine, Mittelstrasse 43, Bern 3012, Switzerland. E-mail: claudia.kuehni@ispm.unibe.ch

Received: 14 March 2019 | Accepted after revision: 11 June 2019

Conflict of interest: F.S. Halbeisen has nothing to disclose. A. Shoemark has nothing to disclose. A. Barbato has nothing to disclose. M. Boon reports grants from Horizon 2020, outside the submitted work. S. Carr reports personal fees for advisory board work, acting as registry trial PI, and travel and accommodation expenses for meetings from Vertex Pharmaceuticals, advisory board honoraria from Chiesi Pharmaceuticals, personal fees for lectures from Actavis Pharmaceuticals, and has acted as trial PI for Pharmaixis Pharmaceuticals, outside the submitted work. S. Crowley has nothing to disclose. R. Hirst has nothing to disclose. B. Karadag has nothing to disclose. C. Koerner-Rettberg has nothing to disclose. M.R. Loebinger reports personal fees for advisory board work from Bayer, Polyphor and Raptor, personal fees for advisory board work lectures from Griffols, and is UK chief investigator for Parion, outside the submitted work. J.S. Lucas reports grants, personal fees for advisory board work, non-financial support for meeting attendance and equipment donations from Aerocrine/Circassia, grants and personal fees for advisory board work from Vertex, grants from Parion, outside the submitted work. B. Maitre has nothing to disclose. H. Mazurek has nothing to disclose. U. Ozcelik has nothing to disclose. V. Martinu has nothing to disclose. N. Schwerk has nothing to disclose. G. Thouvenin has nothing to disclose. S.A. Tschanz has nothing to disclose P. Yiallouros has nothing to disclose. M. Goutaki has nothing to disclose. C.E. Kuehni has nothing to disclose.

Support statement: This work was funded by Schweizerischer Nationalfonds zur Förderung der Wissenschaftlichen Forschung (grant 320030_173044). Funding information for this article has been deposited with the Crossref Funder Registry.

\section{References}

1 Lucas JS, Paff T, Goggin P, et al. Diagnostic methods in primary ciliary dyskinesia. Paediatr Respir Rev 2016; 18: 8-17.

2 Barbato A, Frischer T, Kuehni CE, et al. Primary ciliary dyskinesia: a consensus statement on diagnostic and treatment approaches in children. Eur Respir J 2009; 34: 1264-1276.

3 Lundberg JO, Weitzberg E, Nordvall SL, et al. Primarily nasal origin of exhaled nitric oxide and absence in Kartagener's syndrome. Eur Respir J 1994; 7: 1501-1504.

4 Santamaria F, de Santi MM, Grillo G, et al. Ciliary motility at light microscopy: a screening technique for ciliary defects. Acta Paediatr 1999; 88: 853-857.

5 Afzelius BA. A human syndrome caused by immotile cilia. Science 1976; 193: 317-319.

6 Lucas JS, Barbato A, Collins SA, et al. European Respiratory Society guidelines for the diagnosis of primary ciliary dyskinesia. Eur Respir J 2017; 49: 1601090.

7 Grimshaw J, Eccles M, Tetroe J. Implementing clinical guidelines: current evidence and future implications. J Contin Educ Health Prof 2004; 24: Suppl. 1, S31-S37.

8 Goutaki M, Maurer E, Halbeisen FS, et al. The international primary ciliary dyskinesia cohort (iPCD Cohort): methods and first results. Eur Respir J 2017; 49: 1601181.

9 Collins SA, Gove K, Walker W, et al. Nasal nitric oxide screening for primary ciliary dyskinesia: systematic review and meta-analysis. Eur Respir J 2014; 44: 1589-1599.

10 Leigh MW, Hazucha MJ, Chawla KK, et al. Standardizing nasal nitric oxide measurement as a test for primary ciliary dyskinesia. Ann Am Thorac Soc 2013; 10: 574-581.

11 Rumman N, Jackson C, Collins S, et al. Diagnosis of primary ciliary dyskinesia: potential options for resource-limited countries. Eur Respir Rev 2017; 26: 160058.

12 Omran H, Haffner K, Volkel A, et al. Homozygosity mapping of a gene locus for primary ciliary dyskinesia on chromosome 5p and identification of the heavy dynein chain DNAH5 as a candidate gene. Am J Respir Cell Mol Biol 2000; 23: 696-702.

13 Kim RH DAH, Cutz E, Knowles MR, et al. The role of molecular genetic analysis in the diagnosis of primary ciliary dyskinesia. Ann Am Thorac Soc 2014; 11: 351-359.

14 Fliegauf M, Olbrich H, Horvath J, et al. Mislocalization of DNAH5 and DNAH9 in respiratory cells from patients with primary ciliary dyskinesia. Am J Respir Crit Care Med 2005; 171: 1343-1349.

15 Shoemark A, Frost E, Dixon M, et al. Accuracy of immunofluorescence in the diagnosis of primary ciliary dyskinesia. Am J Respir Crit Care Med 2017; 196: 94-101.

16 Kouis P, Yiallouros PK, Middleton N, et al. Prevalence of primary ciliary dyskinesia in consecutive referrals of suspect cases and the transmission electron microscopy detection rate: a systematic review and meta-analysis. Pediatr Res 2017; 81: 398-405. 